\title{
A Recombinant Adenoviral Vector With a Specific Tropism to CD4-positive Cells: a New Tool for HIV-1 Inhibition
}

\author{
Abtin Behmardi \\ Golestan University of Medical Sciences and Health Services \\ Touraj Farazmandfar ( $\nabla$ tourajf@yahoo.com) \\ Golestan University of Medical Sciences https://orcid.org/0000-0002-8207-6572
}

\section{Research Article}

Keywords: Gene therapy, Adenovirus, Human Immunodeficiency Virus -1, CD4 Receptor, Viral Tropism

Posted Date: November 9th, 2021

DOl: https://doi.org/10.21203/rs.3.rs-996637/v1

License: (c) (i) This work is licensed under a Creative Commons Attribution 4.0 International License. Read Full License

Version of Record: A version of this preprint was published at Drug Delivery and Translational Research on January 31st, 2022. See the published version at https://doi.org/10.1007/s13346-021-01109-y. 


\section{Abstract}

Gene therapy can be an option to overcoming the side effects of chemotherapy and preventing the development of drug-resistant HIV viruses in HIV-infected patients. The need to develop a safe and efficient vector for gene transfer is always necessary and an appropriate option might be adenovirus (Ad). the use of Ad vectors in the gene delivery applications is limited due to the semi-specific tropism. A strategy to overcome this tropism limitation may be the modification of fiber protein domain involved in the viral binding to cells. Therefore, we designed an Ad5 vector with a specific tropism to CD4+ cells containing an expression system limited to HIV-infected cells. We replaced the knob region of Ad5 fiber protein with the extracellular region of HIV-1 envelope. We also used a specific Tat-inducible promoter to express two anti-HIV-1 shRNAs. Tropism of recombinant Ad5 was assayed by comparison of shRNA expression level in CEM and PBMC cells (as CD4+ cells) and HEK293 cells (as CD4- cells). HIV-1 inhibition was assayed by determination of p24 antigen in the HIV-infected CEM cells transduced with the recombinant Ad5 vector. Our results showed that shRNA expression was significantly higher in CEM and PBMC cells than HEK293 cells when were transduced with recombinant Ad5 vector. This new Ad5 vector also inhibited HIV-1 proliferation in a Tat-inducible manner. Our new recombinant Ad5 vector has a specific tropism to CD4-positive cells that can effectively suppress the HIV-1 replication.

\section{Introduction}

The acquired immune deficiency syndrome (AIDS) caused by the human immunodeficiency virus (HIV) is one of the acute problems of today's world that should be considered. Given the promising results of the drugs used to treat this disease, they are not without problems due to side effects such as drug-related toxicity. In addition, drug failure due to virus resistance is common in long-term antiviral chemotherapy $[1-3]$. Thus, there is a need to develop new alternative therapies to cure patients with chronic HIV infection. One of these advanced therapies is genetic-based approaches such as the use of suicide genes $[4,5]$, dominant-negative proteins [6, 7], and oligonucleotide-based materials $[8,9]$. Some of these therapies have shown promising results in inhibiting HIV replication and some of those have continued to a clinical trial. Given the main problem in controlling HIV infection is the ability of the virus to resist drugs and avoid treatment, so the need to design strategies to control virus replication seems essential. These strategies can include targeting the different viral products in early and late steps of the virus life cycle, designing RNAs interference (RNAi) against the conserved regions on virus transcripts, or a combination of the two strategies. These strategies have shown that they can remarkably reduce the escape of the mutated virus $[10,11]$.

Posttranscriptional silencing by RNAi has been used in many studies to develop new approaches in antiviral therapy $[12,13]$. One of the major RNAis is small interfering RNA (siRNA), which is a doublestranded RNA molecule comprising 22-23 nucleotides and two nucleotide protrusions at both ends of 3' and is modified by the Dicer complex. Dicer is an endoribonuclease that actives the RNA-induced silencing complex $[14,15]$. The siRNA can be transfected as synthetic or as an expression plasmid with 
sense and antisense strands separately. Another strategy to construct siRNA is short-stranded RNA (shRNA), a 50-60 nucleotide single-stranded RNA that is modified to a siRNA molecule [16-18].

One of the best approaches in gene therapy for HIV-infected cells is to use a selective inducible promoter for the expression of inhibitory genes. In some previous studies, some of these promoters have been developed, including the native HIV long terminal repeat (LTR) [19-23], chimeric LTR-hsp [22, 23], and chimeric CK-TAR $[24,25]$. All these promoters are induced by trans-activating regulatory protein (Tat) produced by HIV [26], thus they express their controlled genes specifically in HIV-infected cells. The CKTAR promoter can be safer compared to native LTR and LTR-hsp because it lacks the risk of LTR remodeling. However, in an shRNA expression cassette, the CK-TAR promoter cannot generate an shRNA site with the desired transcription start site. Also, It had a relative amount of basal expression in the absence of Tat protein that reduces its eligibility in selective expression [25]. To overcome these risks, we recently developed a Tat-inducible promoter named the CkRhsp, with neutralized LTR mobilization and a favorable transcriptional start site to express an anti-HIV shRNA [27].

In the last decade, Adenoviral (Ad) vectors have been frequently used for gene delivery. They have been well studied and can be produced to high titer. The Ad vectors also efficiently express a transgene in both dividing and non-dividing cells and can be conserved in cells as episomal form [28-30]. The results of almost all clinical trials with this vector indicated that Ad vectors are safe and well-tolerated [31]. Despite the versatility of recombinant Ad vectors in gene therapy approaches, the diversity in the use of these vectors in gene transfer applications is limited due to their semi-specific tropism and is best suited for a specific organ rather than a specific cell type [32]. One strategy to overcome this tropism restriction could be to modify the domains of the proteins involved in binding the virus to the cell through which the vector is allowed to interact with the receptors of a particular cell. Ads bind to a specific receptor in eukaryotic cells via the Knob domain at the end of their fiber protein. Thus, maybe protein engineering of fiber protein will alter the natural tropism of Ads [33,34].

In this study, we decided to design an Ad5 vector with a specific tropism to CD4-positive cells. Thus, we replaced the Knob region of the Ad5 fiber protein with the extracellular domain of the HIV-1 envelope protein. To obtain a restricted expression system for HIV-infected cells, we used a TAT-inducible promoter called CkRhsp to express two anti-HIV-1 shRNAs, as we have reported previously [27].

\section{Materials And Methods}

\section{Virus production}

The two shRNA cassettes used in this study, target two highly conserved sequences in the HIV-1 RNA [27]. Two shRNA expressional cassettes were synthesized in order of CkRhsp promoter, shRNA and minimal polyadenylation signal with a length of 1.3 kilobases (kb) (GeneRay, Shanghai, China). They were then cloned into pShuttle plasmid (Agilent, Santa Clara, USA) digested by Xhol/Bglll (Thermo Fisher, Massachusetts, USA) and the pShuttle-sh plasmid was generated. The chimeric knobless Ad5 fiber gene was designed respectively by the $\mathrm{N}$-terminal tail and the first two repeats of the Shaft domain of the Ad5 
fiber protein, HIV-1 gp140 and Ad5 poly A. This gene along with the right homology arm was synthesized and cloned into pShuttle-sh plasmid digested by Bbsl/BamHI (Thermo Fisher, Massachusetts, USA) and named pShuttle-sh/ $\Delta \mathrm{knob} / \mathrm{gp}$ plasmid. Also, a pShuttle-sh/ $\Delta \mathrm{knob} / \mathrm{gp}$ plasmid was prepared with two irrelevant shRNAs as a mock control. In addition, a recombinant $A d 5$ fiber gene without knob region along with the right homology arm was synthesized as mock control and cloned into Bbsl/BamHI-digested pShuttle-sh plasmid and named pShuttle-sh/ $\triangle$ knob (Fig. 1). This vector is constructed to assay the binding of adenovirus coating proteins other than Knob domain to the CD4 receptors. The resultant plasmids were linearized by Pmel enzyme (Thermo Fisher, Massachusetts, USA) and were cotransformed with a pAdEasy-1 plasmid (replication-defective Ad5 genome) into E. coliBJ5183 strain for homologous recombination according to the AdEasy Adenoviral Vector System instruction (Agilent, Santa Clara, USA). The smallest well-isolated colonies were then removed and cultured in LB-kanamycin broth. The recombinant Ad5 plasmids were extracted and digested by Pacl enzyme (Thermo Fisher, Massachusetts, USA) to confirm by size in agarose electrophoresis. The detailed structures of recombinant Ad5 vectors are shown in Figure 1. The resultant Ad plasmid was transfected into the human embryonic kidney (HEK) 293 cells (ATCC, CRL1573) to produce recombinant Ad5 virus. The virus titer was determined by plaque assay using agarose overlay according to the AdEasy Adenoviral Vector System instruction. Recombinant Ad5 viruses were produced in titers of $10^{7}$ to $10^{8}$ plaque-forming units (PFU)/ml. The HIV -1 virus was produced by transfection of HEK293 cells with a pNL4-3 plasmid (HIV-1 producer) (NIH AIDS Research and Reference Reagent Program, Germantown, USA) using $1 \mu \mathrm{g} / \mathrm{ml}$ Polyethylenimine for 20 hours at $37^{\circ} \mathrm{C}$. Cell culture medium was then replaced with fresh complete Dulbecco's Modified Eagle's medium (DMEM) medium (Sigma-Aldrich, Missouri, USA). Viruses were harvested at 48 and 72-, and 96-hours post-transfection and tittered using p24 Elisa kit (Clontech, California, USA) in an Elisa plate reader (BioTek, Vermont, USA) according to the manufacturer's instructions. HIV titers ranged from $5 \times 10^{8}$ to $7 \times 10^{8}$ infectious units/ml. One picogram (pg) p24 is approximately equivalent to 175000 infectious viruses, which was calculated using the following formula: 1 pg p24 / [36 (fiber numbers in one Ad virus) $[35] \times 24 \mathrm{kDa}$ (p24 weight)] $\times 0.25$ (Ad infectious units rate) [36] $\approx 175000$ infectious units.

\section{HIV-1 gp140 Elisa assay}

To confirm the presence of HIV-1 gp140 protein on the recombinant Ad5 vector, the level of this peptide was measured in $50 \mu \mathrm{L}$ of the recombinant Ad5-sh/ $\Delta \mathrm{knob} / \mathrm{gp}$ vector and compared with its value in the same volume of Ad5-sh/ $\Delta$ knob vector by HIV-1 gp120 Elisa Kit (antibodies-online GmbH, Aachen, Germany) in accordance with the manufacturer's instructions.

\section{Cell culture}

The cells used in this study included CEM cells, a human T-cell line (ATCC, CCL-119) and the peripheral blood mononuclear cells (PBMC) (as CD4-positive), and HEK293 cell line (as CD4-negative). To generate HIV-infected cells to produce TAT protein to induce shRNA expression, cells were seeded in a 6-well tissue culture plate at a density of $2 \times 10^{5}$ cell/well with $1 \mathrm{ml}$ DMEM medium. After 20 hours, cells were infected with HIV-1 in a multiplicity of infection (MOI) of 1 for 20 hours at $37^{\circ} \mathrm{C}$ [37]. The medium was then 
replaced with $2 \mathrm{ml}$ of fresh DMEM containing recombinant Ad5 vectors in an MOI of 10. After 6 hours, the medium was then replaced with $2 \mathrm{ml}$ of fresh DMEM.

\section{Tropism assay and HIV-1 challenge}

To investigate the efficient tropism of the recombinant Ad5 vector to CD4-positive cells, shRNA expression was assayed as an indirect index of successful transduction. For this purpose, Total RNA was isolated from cells at 24 hours post-transduction by the mirVana miRNA Isolation Kit (Thermo Fisher, Massachusetts, USA). The first-strand the complementary DNA (CDNA) was synthesized by stem-loop primers and using reverse transcription enzyme (Thermo Fisher, Massachusetts, USA) according to the kit instructions. The cDNA level was then determined by forward and reverse primers and the SYBR Green Master Mix (YektaTajhiz, Tehran, Iran) as triplicate in the ABI Real-Time PCR system (Applied Biosystems, California, USA). The CDNA expression was normalized with U6-snRNA endogenous control as described previously [38]. The shRNA relative expression was calculated by the $2^{-\Delta \mathrm{Ct}}$ [39]. HIV-1 proliferation was investigated in culture supernatants harvested 24 hours post-transduction and assayed by p24 antigen ELISA kit.

\section{Statistical analysis}

The variables were expressed as the mean \pm standard deviation. Data were analyzed by GraphPad software (GraphPad, La Jolla, USA). Mann Whitney U test was used to compare the means of two groups. Differences of $p$-value less than 0.05 were considered as statistically significant.

\section{Results}

\section{Recombinant Ad5 vector has a specific tropism to CD4-positive cells}

The presence of HIV-1 gp140 protein on the recombinant Ad5 was confirmed by Elisa assay. As results of HIV-1 gp140 Elisa show, gp140 concentration in Ad5-sh/ $\Delta \mathrm{knob} / \mathrm{gp}$ vector $(713.3 \pm 72.19 \mathrm{picomol} / \mathrm{ml})$ is significantly higher than Ad5-sh/ $\Delta$ knob vector (as control without gp140) (not detectable) $(p=0.0006)$ (Fig. 2). These results show that the Ad5 envelope protein is efficiently engineered to pseudotype to CD4positive cells. To investigate specific tropism of the recombinant Ad5-sh/ $\Delta \mathrm{knob} / \mathrm{gp}$ vector to $C D 4$-positive cells, shRNA expression level was determined as an indirect index of successful transduction. The results of Fig. 3 show that shRNA expression is significantly higher in CEM cells $(2.35 \pm 0.33)(p=0.0009)$ and PBMCs $(1.17 \pm 0.24)(p=0.0127)$ compared with HEK293 cells $(0.47 \pm 0.15)$ when were transduced with Ad5-sh/ $\Delta \mathrm{knob} / \mathrm{gp}$ vector. No significant difference was observed in shRNA expression level between CEM cells $(0.31 \pm 0.10)(p=0.3476)$ and PBMCs $(0.42 \pm 0.12)(p=0.9573)$ with HEK293 cells $(0.42 \pm 0.13)$ when were transduced with Ad5-sh/ $\Delta$ knob vector.

\section{Recombinant Ad5 vector inhibits HIV-1 proliferation}

To investigate the efficiency of HIV-1 inhibition by the new recombinant Ad5 vector, the HIV-infected cells were transiently transduced by the recombinant Ad5 vector, and p24 protein level was determined as an 
HIV-1 proliferation index. As results of Fig. 4 show, the p24 level is significantly lower in CD4-positive cells (CEM and PBMC) transduced with Ad5-sh/ $\triangle \mathrm{knob} / \mathrm{gp}$ vector (2341 \pm 413 and $1332 \pm 312$ respectively) compared with untransduced cells (10324 \pm 1122 and $5768 \pm 654$ respectively) $(p<0.001)$. There was no significant difference in p24 level between cells transduced with Ad5-sh/ $\Delta \mathrm{knob}$ and Ad5-sh.irrel/ $\Delta \mathrm{knob} / \mathrm{gp}$ with untransduced cells.

\section{Discussion}

Gene therapy can be an option for overcoming the side effects of chemotherapy and preventing the development of drug-resistant HIV [10]. The exclusive properties of HIV-1 and the existence of multiple mechanisms for disease development, make it difficult to design an effective gene therapy strategy. However, we previously reported a lentiviral vector containing a TAT-inducible expression system with specific tropism to CD4-positive cells to inhibit HIV-1 replication [27]. But the need to develop a safer and more efficient vector for gene transfer seems to be necessary, and the appropriate option may be to use an adenoviral vector. Although, in the past, efforts have been made to engineer fiber protein to modify Ad tropism [28, 32-35]. But so far, an Ad vector with a specific tropism to CD4 positive cells has not been reported. Thus, in this study, we decided to create a recombinant Ad5 vector with a modified fiber to gene transfer into CD4-positive cells. Given the similarity of the trimeric structure of the Ad5 fiber protein and the HIV-1 envelop protein, it was hypothesized that the replacement of the Knob region of Ad5 fiber with the extracellular region of HIV-1 envelop could lead to the creation of a recombinant Ad5 vector with a specific tropism to CD4-positive cells. In designing this new vector, our theory was that identification of the receptors of CD4 and CCR5 alone could lead to viral endocytosis in CD4-positive cells. As results in Fig. 3 show, our recombinant Ad5 vector has a significant tropism to CD4-positive cells compared with CD4-negative cells. Indirectly analysis of the binding of the Ad5-sh/ $\Delta \mathrm{knob} / \mathrm{gp}$ and Ad5-sh/ $\Delta \mathrm{knob}$ vectors showed that the binding of the Ad5-sh/ $\Delta \mathrm{knob} / \mathrm{gp}$ vector to the $\mathrm{CD} 4$ receptor was probably dependent on gp140, and that other vector envelope proteins other than the Knob domain play little role in binding to this receptor.

RNAi gene silencing is an efficient mechanism for downregulating specific genes. Thus, it can be used as a useful antiviral agent in strategies of gene therapy. One of the advantages of the RNAi-based approaches in comparison with protein-based is the low immunogenicity of the RNAi molecule [40]. As reported in our study and other studies previously, the use of multiple shRNAs to target highly conserved HIV sequences can be an effective method to inhibit virus replication in RNAi-based approaches [27, 41]. Thus, in this study, we decided to use the same dual-shRNA expression system in the recombinant Ad5 vector to inhibit HIV-1 replication. This expression system is under the control of the CkRhsp promoter, which is active only in cells infected with HIV. As the results in Fig. 4 show, this expressional system can efficiently and transiently inhibit HIV replication.

\section{Conclusions}


In this study, we developed a novel recombinant Ad5 vector with a specific tropism to CD4-positive cells. This vector has an expression system through which can effectively and transiently suppress the HIV-1 replication. This vector can be used as a complementary HIV therapy or an anti-HIV vaccine in the future.

\section{Declarations}

\section{Ethical statement}

\section{Ethics approval and consent to participate}

Not Applicable

\section{Consent for publication}

All authors give consent for publication.

\section{Availability of data and materials}

All data and materials support the claims in this manuscript and comply with field standards.

\section{Competing interests}

The authors declare no competing interests.

\section{Funding}

The study was supported by a grant from the research department in Golestan University of Medical Sciences, Gorgan, Iran (Grant number: G/P/35/306082).

\section{Authors' contributions}

T.F. conceived and designed the experiments. A.B. conducted the laboratory experiments. A.B. and T.F. analyzed the data. A.B. and T.F. prepared and reviewed the manuscript.

\section{Acknowledgements}

The study was supported by a grant from the research department in the Golestan University of Medical Sciences, Gorgan, Iran (Grant number: G/P/35/306082).

\section{References}

1. Clutter DS, Jordan MR, Bertagnolio S, Shafer RW. HIV-1 drug resistance and resistance testing. Infect Genet Evol. 2016. https://doi.org/10.1016/j.meegid.2016.08.031.

2. Margolis DM, Archin NM, Cohen MS, Eron JJ, Ferrari G, Garcia JV, et al. Curing HIV: Seeking to Target and Clear Persistent Infection. Cell. 2020. https://doi.org/10.1016/j.cell.2020.03.005. 
3. Parikh UM, McCormick K, van Zyl G, Mellors JW. Future technologies for monitoring HIV drug resistance and cure. Curr Opin HIV AIDS. 2017. https://doi.org/10.1097/COH.0000000000000344.

4. Düzgüneş N. Origins of Suicide Gene Therapy. Methods Mol Biol. 2019. https://doi.org/10.1007/9781-4939-8922-5_1.

5. Lal S, Lauer UM, Niethammer D, Beck JF, Schlegel PG. Suicide genes: past, present and future perspectives. Immunol Today. 2000. https://doi.org/10.1016/s0167-5699(99)01550-9.

6. Dupraz P, Cottet S, Hamburger F, Dolci W, Felley-Bosco E, Thorens B. Dominant Negative MyD88 Proteins Inhibit Interleukin-1 $\beta /$ Interferon- $\gamma$-mediated Induction of Nuclear Factor kB-dependent Nitrite Production and Apoptosis in $\beta$ Cells. J Biol Chem. 2000. https://doi.org/10.1074/jbc.M005150200.

7. Pochampally RR, Horwitz EM, DiGirolamo CM, Stokes DS, Prockop DJ. Correction of a mineralization defect by overexpression of a wild-type cDNA for COL1A1 in marrow stromal cells (MSCs) from a patient with osteogenesis imperfecta: a strategy for rescuing mutations that produce dominantnegative protein defects. Gene Ther. 2005. https://doi.org/10.1038/sj.gt.3302514.

8. Wands J, Geissler M, Putlitz J, Blum H, Weizsäcker FV, Mohr L, et al. Nucleic acid-based antiviral and gene therapy of chronic hepatitis B infection. J Gastroenterol Hepatol. 1997. https://doi.org/10.1111/j.1440-1746.1997.tb00521.x.

9. Sardone V, Zhou H, Muntoni F, Ferlini A, Falzarano MS. Antisense Oligonucleotide-Based Therapy for Neuromuscular Disease. Molecules. 2017. https://doi.org/10.3390/molecules22040563.

10. Li M-J, Bauer G, Michienzi A, Yee J-K, Lee N-S, Kim J, et al. Inhibition of HIV-1 infection by lentiviral vectors expressing Pol III-promoted anti-HIV RNAs. Mol Ther. 2003. https://doi.org/10.1016/s15250016(03)00165-5.

11. Unwalla HJ, Rossi JJ. A dual function TAR Decoy serves as an anti-HIV siRNA delivery vehicle. Virol J. 2010. https://doi.org/10.1186/1743-422X-7-33.

12. Haasnoot $J$, Berkhout $B$. Nucleic acids-based therapeutics in the battle against pathogenic viruses. Handb Exp Pharmacol. 2009. https://doi.org/10.1007/978-3-540-79086-0_9.

13. Spurgers KB, Sharkey CM, Warfield KL, Bavari S. Oligonucleotide antiviral therapeutics: antisense and RNA interference for highly pathogenic RNA viruses. Antiviral Res. 2008. https://doi.org/10.1016/j.antiviral.2007.12.008.

14. Bernstein E, Caudy AA, Hammond SM, Hannon GJ. Role for a bidentate ribonuclease in the initiation step of RNA interference. Nature. 2001. https://doi.org/10.1038/35053110.

15. Chendrimada TP, Gregory RI, Kumaraswamy E, Norman J, Cooch N, Nishikura K, et al. TRBP recruits the Dicer complex to Ago2 for microRNA processing and gene silencing. Nature. 2005. https://doi.org/10.1038/nature03868.

16. Caplen NJ, Parrish S, Imani F, Fire A, Morgan RA. Specific inhibition of gene expression by small double-stranded RNAs in invertebrate and vertebrate systems. Proc Natl Acad Sci USA. 2001. https://doi.org/10.1073/pnas.171251798.

17. Lee NS, Dohjima T, Bauer G, Li H, Li M-J, Ehsani A, et al. Expression of small interfering RNAs targeted against HIV-1 rev transcripts in human cells. Nat Biotechnol. 2002. 
https://doi.org/10.1038/nbt0502-500.

18. Xia H, Mao Q, Paulson HL, Davidson BL. siRNA-mediated gene silencing in vitro and in vivo. Nat Biotechnol. 2002. https://doi.org/10.1038/nbt739.

19. Humeau LM, Binder GK, Lu X, Slepushkin V, Merling R, Echeagaray P, et al. Efficient lentiviral vectormediated control of HIV-1 replication in CD4 lymphocytes from diverse HIV+ infected patients grouped according to CD4 count and viral load. Mol Ther. 2004.

https://doi.org/10.1016/j.ymthe.2004.03.005.

20. Snyder LL, Esser JM, Pachuk CJ, Steel LF. Vector design for liver-specific expression of multiple interfering RNAs that target hepatitis B virus transcripts. Antiviral Res. 2008. https://doi.org/10.1016/j.antiviral.2008.04.001.

21. Park J, Nadeau PE, Mergia A. Activity of TAR in inducible inhibition of HIV replication by foamy virus vector expressing siRNAs under the control of HIV LTR. Virus Res. 2009. https://doi.org/10.1016/j.virusres.2008.11.016.

22. Unwalla HJ, Li M-J, Kim JD, Li HT, Ehsani A, Alluin J, et al. Negative feedback inhibition of HIV-1 by TAT-inducible expression of siRNA. Nat Biotechnol. 2004. https://doi.org/10.1038/nbt1040.

23. Unwalla HJ, Li H-T, Bahner I, Li M-J, Kohn D, Rossi JJ. Novel Pol Il fusion promoter directs human immunodeficiency virus type 1-inducible coexpression of a short hairpin RNA and protein. J Virol. 2006. https://doi.org/10.1128/JVI.80.4.1863-1873.2006.

24. Han P, Brown R, Barsoum J. Transactivation of heterologous promoters by HIV-1 tat. Nucleic Acids Res. 1991. https://doi.org/10.1093/nar/19.25.7225.

25. Sanghvi VR, Steel LF. Expression of interfering RNAs from an HIV-1 Tat-inducible chimeric promoter. Virus Res. 2011. https://doi.org/10.1016/j.virusres.2010.09.006.

26. Jeang KT, Xiao H, Rich EA. Multifaceted activities of the HIV-1 transactivator of transcription, Tat. J Biol Chem. 1999. https://doi.org/10.1074/jbc.274.41.28837.

27. Farazmandfar T, Haghshenas MR, Shahbazi M. Inhibition of HIV-1 by a Lentiviral Vector with a Novel Tat-Inducible Expression System and a Specific Tropism to the Target Cells. Hum Gene Ther. 2015. https://doi.org/10.1089/hum.2015.031.

28. Kim SY, Kang S, Song JJ, Kim J-H. The effectiveness of the oncolytic activity induced by Ad5/F35 adenoviral vector is dependent on the cumulative cellular conditions of survival and autophagy. Int $J$ Oncol. 2013. https://doi.org/10.3892/ijo.2013.1812.

29. Sharma A, Tandon M, Bangari DS, Mittal SK. Adenoviral vector-based strategies for cancer therapy. Curr Drug ther. 2009. https://doi.org/10.2174/157488509788185123.

30. Fukazawa T, Matsuoka J, Yamatsuji T, Maeda Y, Durbin ML, Naomoto Y. Adenovirus-mediated cancer gene therapy and virotherapy. Int J Mol Med. 2010. https://doi.org/10.3892/ijmm_00000306.

31. Wold WSM, Toth K. Adenovirus vectors for gene therapy, vaccination and cancer gene therapy. Curr Gene Ther. 2013. https://doi.org/10.2174/1566523213666131125095046. 
32. Krasnykh VN, Mikheeva GV, Douglas JT, Curiel DT. Generation of recombinant adenovirus vectors with modified fibers for altering viral tropism. J Virol. 1996. https://doi.org/10.1128/JVI.70.10.68396846.1996.

33. Henry LJ, Xia D, Wilke ME, Deisenhofer J, Gerard RD. Characterization of the knob domain of the adenovirus type 5 fiber protein expressed in Escherichia coli. J Virol. 1994. https://doi.org/10.1128/JVI.68.8.5239-5246.1994.

34. Stevenson SC, Rollence M, White B, Weaver L, McClelland A. Human adenovirus serotypes 3 and 5 bind to two different cellular receptors via the fiber head domain. J Virol. 1995. https://doi.org/10.1128/JVI.69.5.2850-2857.1995.

35. Barry MA, Rubin JD, Lu S-C. Retargeting adenoviruses for therapeutic applications and vaccines. FEBS Lett. 2020. https://doi.org/10.1002/1873-3468.13731.

36. Li E, Stupack D, Bokoch GM, Nemerow GR. Adenovirus Endocytosis Requires Actin Cytoskeleton Reorganization Mediated by Rho Family GTPases. J Virol. 1998. https://doi.org/10.1128/JVI.72.11.8806-8812.1998.

37. Holmes M, Zhang F, Bieniasz PD. Single-Cell and Single-Cycle Analysis of HIV-1 Replication. PLoS Pathog. 2015. https://doi.org/10.1371/journal.ppat.1004961.

38. Yazdani Y, Farazmandfar T, Azadeh H, Zekavatian Z. The prognostic effect of PTEN expression status in colorectal cancer development and evaluation of factors affecting it: MiR-21 and promoter methylation. J Biomed Sci. 2016. https://doi.org/10.1186/s12929-016-0228-5.

39. Rezayani S, Farazmandfar T, shahbazi M. Association assessment of platelet derived growth factor B gene polymorphism and its expression status with susceptibility to coronary artery disease. EJMHG. 2017. https://doi.org/10.1016/j.ejmhg.2017.03.004.

40. McManus MT, Sharp PA. Gene silencing in mammals by small interfering RNAs. Nat Rev Genet. 2002. https://doi.org/10.1038/nrg908.

41. Das AT, Brummelkamp TR, Westerhout EM, Vink M, Madiredjo M, Bernards R, et al. Human immunodeficiency virus type 1 escapes from RNA interference-mediated inhibition. J Virol. 2004. https://doi.org/10.1128/jvi.78.5.2601-2605.2004.

\section{Figures}



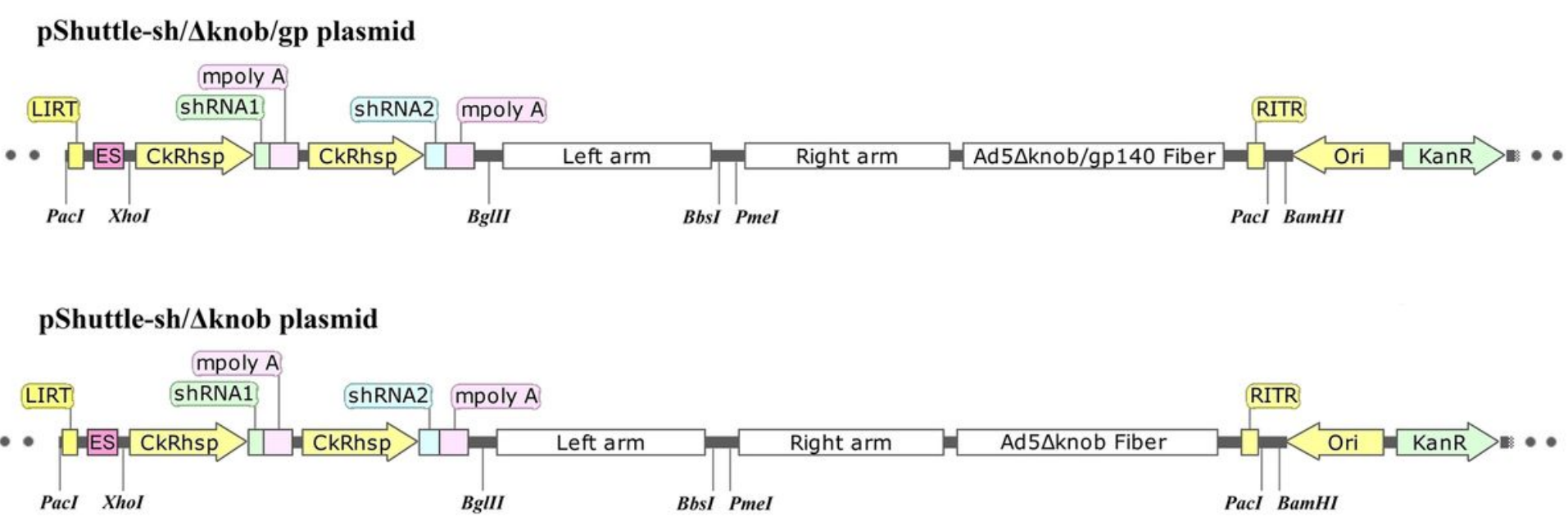

\section{Recombinant Ad5-sh/Aknob/gp vector}

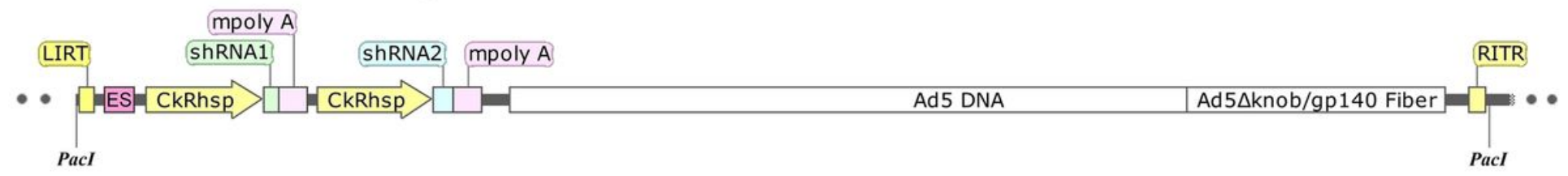

\section{Recombinant Ad5-sh/ $\Delta$ knob vector}

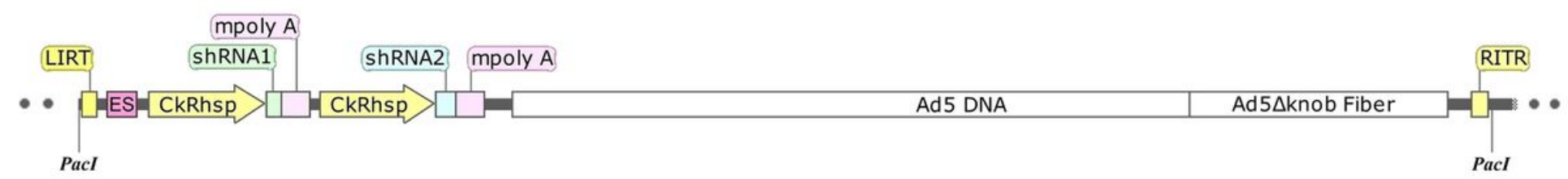

\section{Figure 1}

Schematic structure of shuttle plasmids and adenoviral vectors. pShuttle-sh/ $\Delta \mathrm{knob} / \mathrm{gp}$ plasmid contains two the Inverted Terminal Repeat (ITR) sequences which surround several sequences including encapsidation signal (ES), two shRNA expression cassettes [CkRhsp promoter, shRNA sequence and minimal polyadenylation (mpolyA) signal respectively], two homology arms and a chimeric Ad5 fiber gene in which knob region has been replaced with HIV-1 gp140 domain. The pShuttle-sh/ $\Delta \mathrm{knob}$ plasmid is similar to the pShuttle-sh/ $\Delta \mathrm{knob} / \mathrm{gp}$ plasmid except that its fiber gene does not have the HIV-1 gp140 sequence. The recombinant Ad5-sh/ $\Delta \mathrm{knob} / \mathrm{gp}$ vector is the product of recombination between shuttle

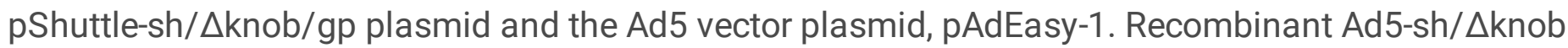
vector is the product of recombination between shuttle pShuttle-sh/ $\Delta \mathrm{knob}$ plasmid and pAdEasy- 1 plasmid. 


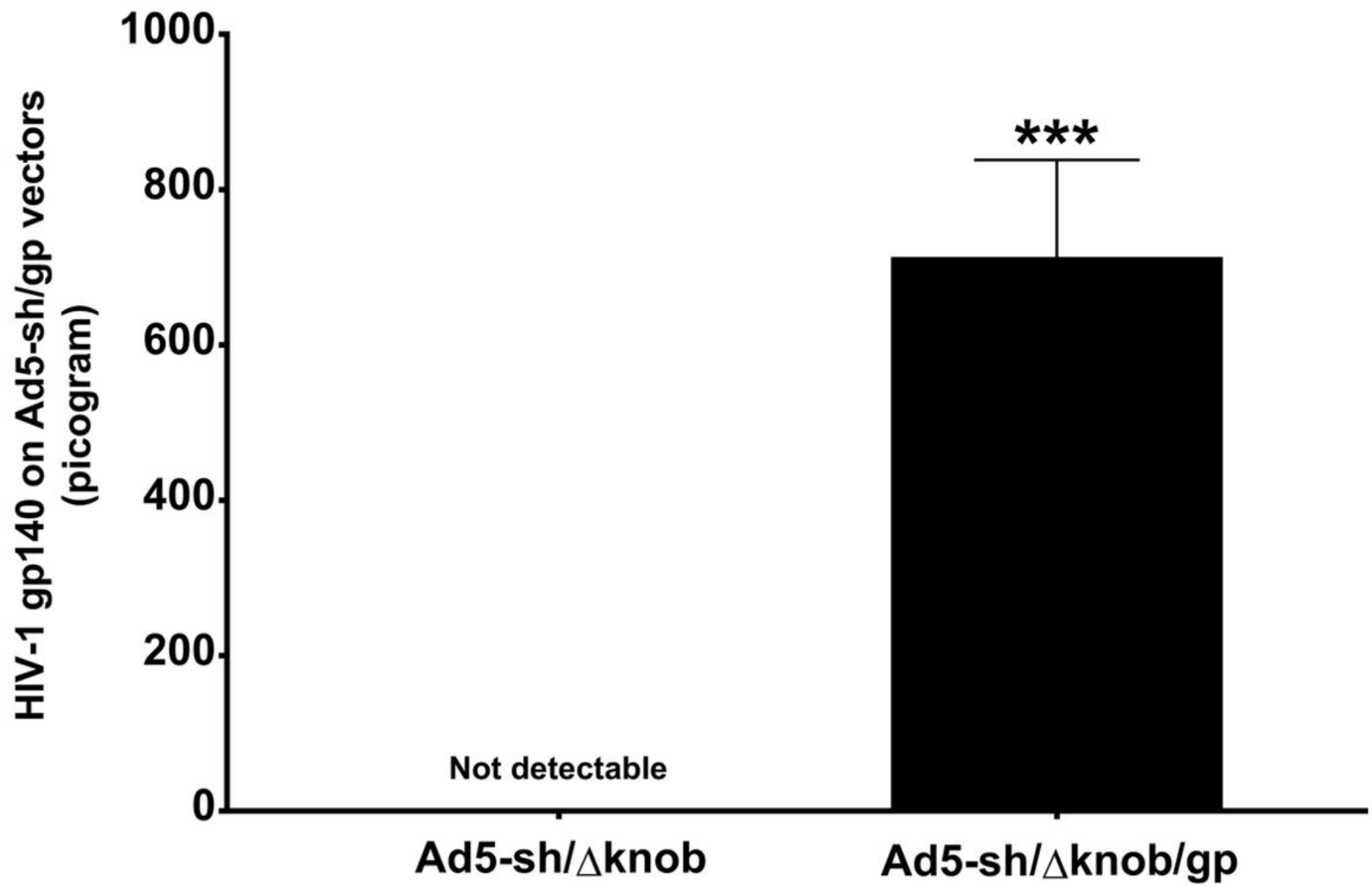

Figure 2

Elisa assay to confirm the presence of HIV-1 gp140 protein. The HIV-1 gp140 protein concentration in Ad5-sh/ $\Delta \mathrm{knob} / \mathrm{gp}$ vectors was significantly higher compared with Ad5-sh/ $\Delta \mathrm{knob}$ vectors (as a control without gp140). The results are derived from three replicates of three independent experiments. $(* \star \star), p<$ 0.001 . 


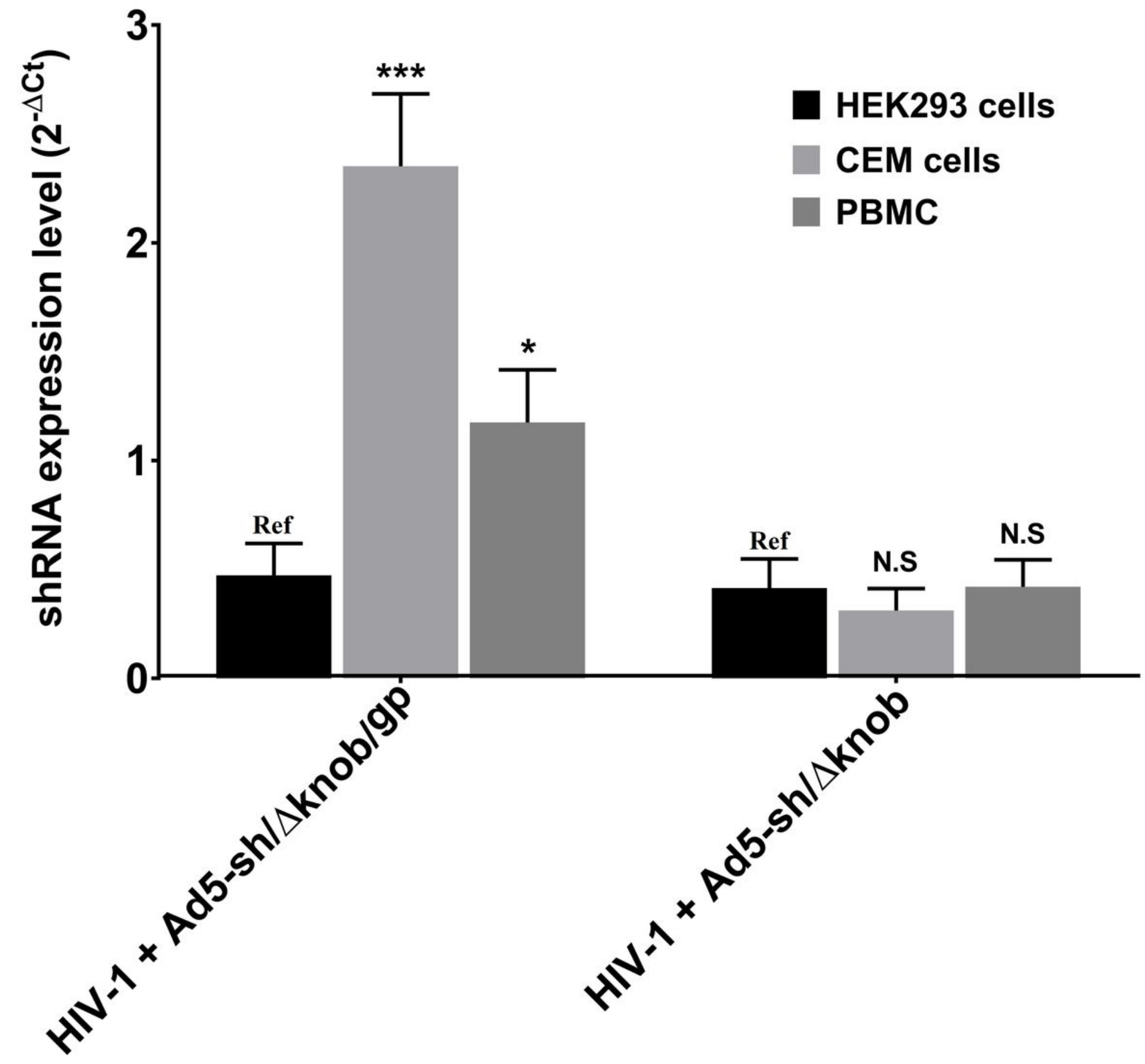

Figure 3

The shRNA expression assay. To investigate the specific tropism of the recombinant Ad5 vector to CD4positive cells, the shRNA expression as an index of successful transduction was determined. ShRNAs were measured in CEM and PBMC cells (as CD4-positive) and HEK293 cells (as CD4-negative) transduced with Ad5-sh/ $\Delta \mathrm{knob} / \mathrm{gp}$ and Ad5-sh/ $\Delta$ knob vectors. ShRNA expression was significantly higher in CEM and PBMC cells compared with HEK293 cells when transfected with Ad5-sh/ $\Delta$ knob/gp vector. There was no significant difference in shRNA expression level between CEM and PBMC cells with HEK293 cells when transfected with Ad5-sh/ $\triangle \mathrm{knob}$ vector. The results are derived from three replicates of three independent experiments. Sh, shRNA; Ref, reference group; $(*), p<0.05 ;(* * *), p<0.001$. 


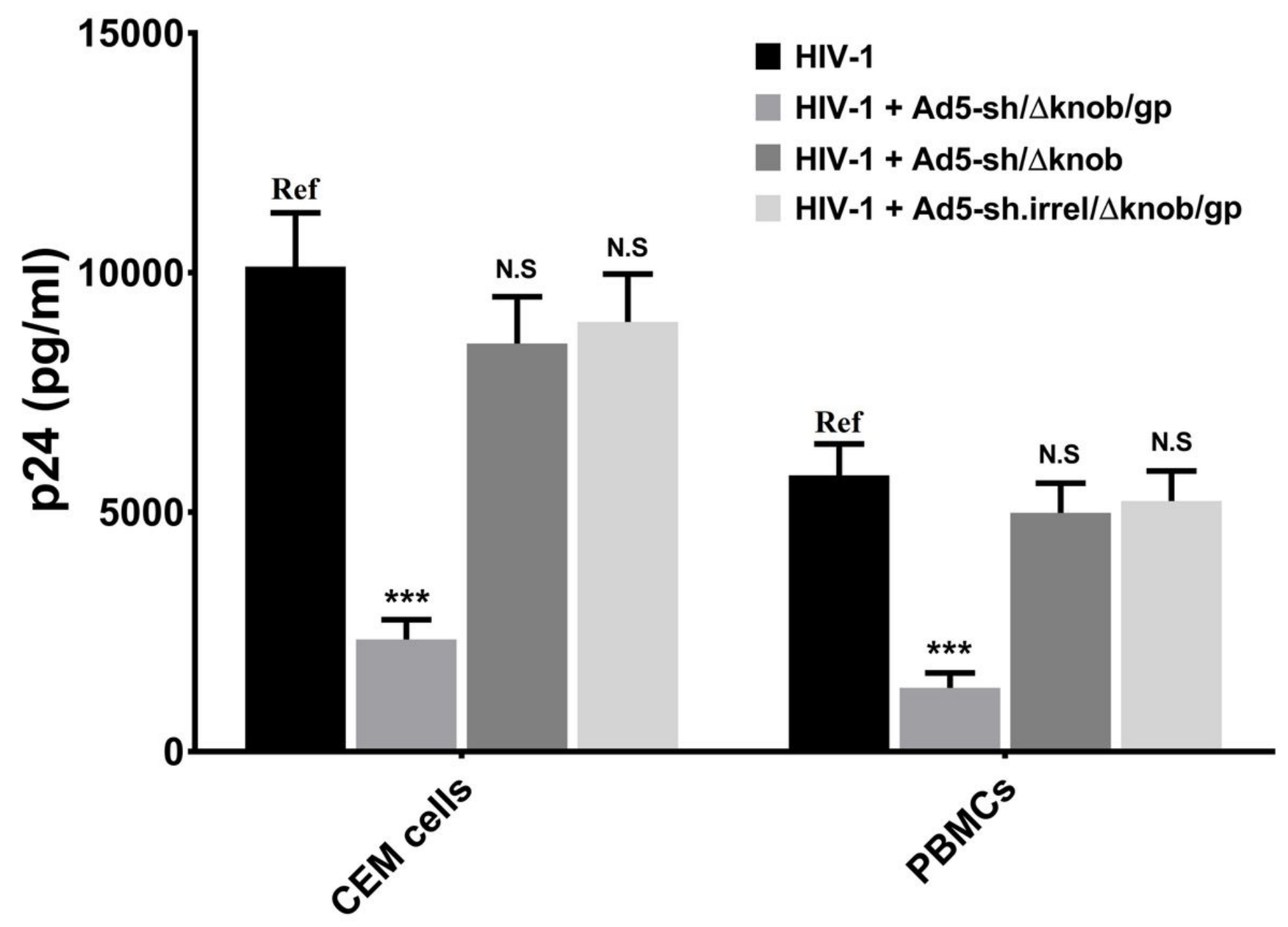

Figure 4

The HIV-1 challenge assay. To investigate the inhibitory effect of the recombinant vector on HIV-1 virus replication, p24 protein levels were determined in CEM and PBMC cells transfected with Ad5-sh/ $\Delta \mathrm{knob} / \mathrm{gp}$ and $\mathrm{Ad5}$-sh/ $\Delta \mathrm{knob}$ vectors at $\mathrm{MOI} 10$. The $\mathrm{p} 24$ protein level was significantly lower in cells transfected with the Ad5-sh/ $\Delta \mathrm{knob} / \mathrm{gp}$ vector than in untransfected cells. The results are derived from three replicates of three independent experiments. Sh, shRNA; gp, glycoprotein 140; irrel, irrelevant; Ref, reference group; $(* \star \star), p<0.001$.

\section{Supplementary Files}

This is a list of supplementary files associated with this preprint. Click to download.

- GrapicalAbstract.tif 